\title{
Research of Wind Turbine Drive System Fault Diagnosis of Mechanical and Electrical Simulation Mode
}

\author{
Xianjiang Shi ${ }^{*}$, Jingchun Zhang, Jiankun Zhang and Heng Du \\ School of Mechanical and Power Engineering, Harbin University and Technology, Harbin, 150080 \\ *Corresponding author
}

\begin{abstract}
In order to study a method of diagnosing wind turbine gear fault by generator electrical signal and extend its field of application. A typical doubly-fed wind turbine is taken as object. The gear pair dynamics model and the mathematical model of generator unit are established on the basis of considering the gear mesh stiffness changes and broken gear fault characteristics. The model of doubly-fed generator and its control system are also built. These two models are interrelated through rotational speed parameter of gear pair and generator. Electrical and mechanical joint simulation model is set, which simulates current of stator at normal and fault state. Current fault characteristics are analyzed when the gear is normal or have a tooth broke in theory. A set of simulation test bench are established, wind turbine gear fault simulation experiment is operated. Collected current and voltage signals from the experiment are compared with rotate speed signal, which can verify the feasibility of the stator current method. Simulation results are compared with fault test simulation.
\end{abstract}

Keywords-wind generators; stator electrical signal; gear fault; fault diagnostic; simulation

\section{INTRODUCTION}

At present, the proportion of wind power in the power system is constantly increasing, which has become the third largest energy after thermal power and hydropower [1]. However, the cost of maintenance is higher and higher with the growing of wind turbine monomer generating capacity. Statistically, the maintenance costs accounted for $25 \% \sim 30 \%$ of the total cost [2]. But most wind field does not contain the vibration test project, the main reason is that the cost of vibration diagnosis sensor is high, and inconvenient of installation and signal transmission. For this reason, this article discusses a way to use the generator electrical signals indirect diagnosis for mechanical fault diagnosis, called motor current signal analysis method, it is also known as non-sensor diagnostic method.

There have been many reports about this method at home and abroad. For example, foreign scholars Royo [3] established a simple simulation test bench with asynchronous generator system. Test method was used to analysis the stator current spectrum of bearing fault. In literature [4], a relatively perfect wind turbine fault simulation test bench was established. According to the test of machine fault diagnosis and analysis results by wavelet transform method, the advantages of electric parameter diagnosis method was proved.
Amirat $[5,6]$ make the fault diagnosis double-fed induction generator bearing through the stator current amplitude demodulation method, and achieved good results. These findings indicate that no sensor diagnostic method is feasible in fault diagnosis of wind generator.

\section{The MaIn StRUCtURE AND COMPONENTS OF Wind TURBINE}

A typical mechanical components and control system of DFIG wind turbines include blades, shaft and main bearing, growth gearbox and doubly-fed generator, etc. Generator stator is directly connected to grid and the rotor is connected to the grid through two back-to-back AC - DC - AC converter. When the rotor rotating frequency of generator fr 2 changes, automatic control system control the rotor excitation current $\mathrm{f} 2$ to ensure the stator output frequency f1 is equal to the grid frequency, namely:

$$
f_{1}=p_{n} f_{r_{2}}+f_{2}
$$

In the type $p_{n}$ is the number of generator pole-pairs

\section{MATHEMATICAL MODEL OF DFIG ASYNCHRONOUS GENERATOR}

According to AC motor theory, the dynamic characteristics of the asynchronous generator in the $\mathrm{d}$-q rotating coordinate system can be described by the following equation [7-8].

The voltage equation:

$$
\begin{aligned}
& u_{s d}=-p \Psi_{s d}+\omega_{s} \Psi_{s d}-R_{s} i_{s d} \\
& u_{s q}=-p \Psi_{s q}+\omega_{s} \Psi_{s q}-R_{s} i_{s q} \\
& u_{r d}=p \Psi_{r d}+\omega_{s} \Psi_{r d}+R_{r} i_{r d} \\
& u_{r q}=p \Psi_{r q}+\omega_{s} \Psi_{r q}+R_{r} i_{r q}
\end{aligned}
$$

$u_{s q}, u_{s d}, i_{s q}$ and $i_{s d}$-The $d-q$ coordinate component of the stator voltage and current vector; $u_{r q}, u_{r d}, i_{r q}$ and $i_{r d}$ - The $d-q$ coordinate components of the rotor voltage and current vectors;

$R_{s}, R_{r}$-The resistance of the stator and rotor; $\Psi_{s q}, \Psi_{r q}, \Psi_{s d}$, $\Psi_{r d}$-The $d-q$ coordinate components of the rotor ,stator flux vector; $\omega_{\mathrm{s}}=\omega_{1}-\omega_{r}, d-q$ coordinate system relative to the angular 
velocity of the rotor, Including $\omega_{1}, \omega_{s}$ for the synchronous speed and rotor angular velocity; $p$-differential operator, $p=d / d t$.Flux-linkage equation:

$$
\left\{\begin{array}{l}
\Psi_{s d}=L_{s} i_{s d}-L_{m} i_{r d} \\
\Psi_{s q}=L_{s} i_{q d}-L_{m} i_{r d} \\
\Psi_{r d}=L_{r} i_{r d}-L_{m} i_{s d} \\
\Psi_{r q}=L_{r} i_{r q}-L_{m} i_{s q}
\end{array}\right.
$$

In the formula: $L_{s}, L_{r}, L_{m}$ - The self inductance and mutual inductance of the stator and rotor.

The asynchronous generator electromagnetic torque Te equation at $\mathrm{d}-\mathrm{q}$ coordinates system:

$$
T_{e}=\frac{3}{2} p_{n}\left(i_{s q} \Psi_{s d}-i_{s d} \Psi_{s q}\right)
$$

Equation of motion of the induction generator:

$$
T_{L}=T_{e}+J \frac{1}{p_{n}} \frac{d \omega_{m}}{d t}
$$

In the formula: $T_{L}-\mathrm{drag}$ torque from Wind turbines;

$\omega_{m}-$ rotating mechanical angular velocity of Wind turbines; $J$ - rotational inertia of the system.

\section{Simulation Model of Doubly-Fed Wind Turbine}

\section{A. Systematic Dynamics Simulation Model of Wind Turbine Gear}

(1) Establish drive gear entity model

According to the size of the teeth number, $\mathrm{Z} 1$ is $32, \mathrm{Z2}$ is 23 , modulus $m$ is 3 and tooth width $B$ is 20 . Threedimensional model is established in this paper by UG, which is imported into Adams in Parasolid format.

(2) Create constraint pair and constraint-driven

Rotating vice JOINT_1 and JOINT_2 are inflicted on large gear and small gear. Gear pair is added, before gear pair is created, direction coordinate system of spur gear pair is established. According to gear origin coordinates and transmission ratio, origin point Maker of direction coordinate system is calculated, gear pair GEAR 1 is created in the Maker point. Speed drive is applied, rotating drive MOTION_1 is applied on rotating drive JOINT_1 of the large gear, driving speed is set $30^{\circ} \cdot \mathrm{s}-1$. As shown in Figure 1, it is the established $3 \mathrm{~d}$ model and Adams virtual prototype model.

Similarly, Adams simulation model is established for gear pairs with broken teeth fault according to above method, constraint pair is created, drive is added, simulation parameters are set and simulation data is concluded from the post-processing module.

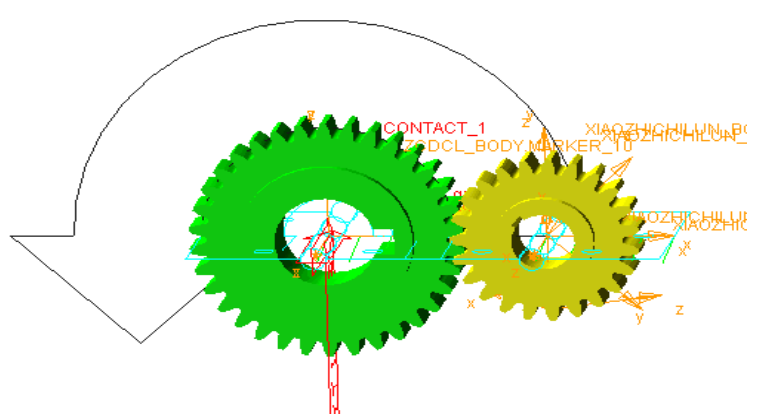

FIGURE I. 3D MODEL AND ADAMS VIRTUAL PROTOTYPE MODEL

\section{B. The Simulation Model of Doubly-fed Wind Power Generator}

The simulation model of Ac doubly-fed generator is shown in Figure 2.

Doubly-fed generator model is replaced by rotor asynchronous motor module, which is set by generator operation mode. Sator windings of generator is linked to three phase impedance load, PWM power converter module is applied to supply unidirectional excitation power to the rotor of the generator, which only simulates the working condition of off-grid.

The basic parameters of simulation system are as follows: rated power of generator is $3 \mathrm{~kW}$, rated voltage is $220 \mathrm{vac}$, rated speed is 1400 RPM, the number of ploes pn is 2, stator resistance Rs is $1.9188 \Omega$, inductance $\mathrm{Ls}$ is $0.24122 \mathrm{H}$, converted to the side of rotor resistance $\operatorname{Rr}$ is $2.5712 \Omega$, inductance $\mathrm{Lr}$ is $0.24122 \mathrm{H}$, mutual inductance of stator and rotor $\mathrm{Lm}$ is $0.234 \mathrm{H}$. The reference coordinate system is synchronous reference coordinate system, the initial state is 0 .

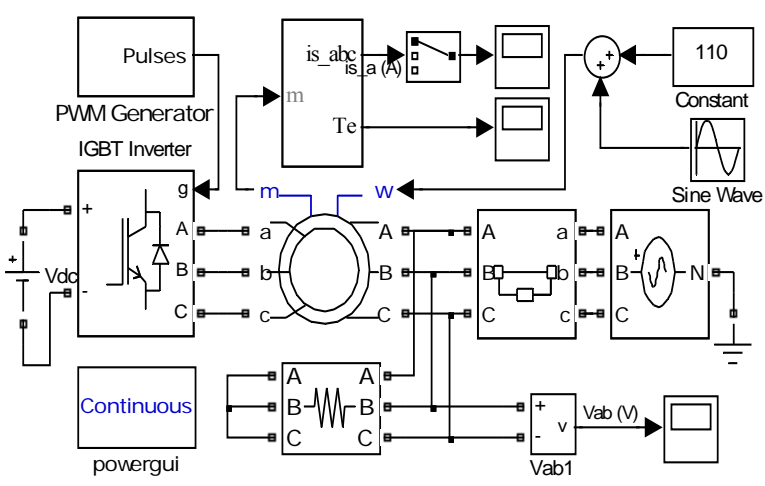

FIGURE II. DOUBLY-FED INDUCTION GENERATOR AND CONTROL SYSTEM SIMULATION MODEL

\section{Wind Turbine Fault Simulation Test Bench}

The overall structure of the simulation test bench is consisting of the simulated wind generator unit (including the ac asynchronous motor, speed gear box and simulated DFIG generator), generator control system, data acquisition system and computer. Fan simulating motor adopts $1.5 \mathrm{~kW}$ AC 
asynchronous motor and inverter driver. $1.5 \mathrm{~kW}$ winding type three-phase asynchronous motor is adopted as a doubly-fed induction generator. The pole number of two motors is 3 and the rated speed of the motor is $920 \mathrm{rpm}$. Because of the limited conditions, the stator winding of generator is connected with three phase impedance load, without grid-connected. The three-phase inverter is applied to output different frequencies of $100 \mathrm{~V}$ rotor phase voltage and take excitation to the rotor winding unidirectional, only sub synchronous and synchronous running state of the generator is simulated. Gear pairs are adopted to simulate the speed growth box of wind generating set, in which the motor gear teeth is 23 , generator gear teeth is 34 and speed growth ratio is about 1.478.

\section{HiLbert Amplitude TRANSFORMATION AND FREQUENCY DEM}

$\mathrm{X}(\mathrm{t})$ is set as a real time domain signal, the Hilbert transform is defined as:

$$
h(t)=\frac{1}{\pi} \int_{-\infty}^{+\infty} \frac{x(\tau)}{t-\tau} d \tau=x(t) * \frac{1}{\pi t}
$$

Then the original signal $\mathrm{x}(\mathrm{t})$ and its Hilbert transform signal can constitute a new analytic signal $\mathrm{z}(\mathrm{t})$ :

$$
z(t)=x(t)+j h(t)=a(t) e^{j \varphi t}
$$

Its amplitude:

$$
a(t)=|z(t)|=\sqrt{x^{2}(t)+h^{2}(t)}
$$

which equals to the amplitude demodulation signal of original signal $\mathrm{x}(\mathrm{t})$, amplitude demodulation spectrum or envelope spectrum can be obtained by FFT analysis.

$$
\varphi(t)=\arctan \frac{h(t)}{x(t)}
$$

It is phase demodulation signal. The derivative of phase demodulation signal is instantaneous frequency, namely instantaneous frequency demodulation signal:

$$
\omega(t)=\frac{d \varphi(t)}{d t}
$$

Or

$$
f(t)=\frac{1}{2 \pi} \frac{d \varphi(t)}{d t}
$$

Instantaneous frequency demodulation spectrum can be got by FFT analysis.

\section{Gear Fault Simulation Results Analysis}

In the simulation, in the gear fault simulation modules of $\mathrm{fz}$ input by one normal gear meshing signal, simulated $\mathrm{K}(\mathrm{t})$ ideal variation, the frequency gear mesh fz; Another input access containing fault signal of gear engagement ,simulated gear has a partial failure.

\section{A. The Simulation Results of Normal Operation}

When the simulation, the average speed of the rotor $\omega \mathrm{r} 2=109.9557 \mathrm{rad} / \mathrm{s}$, Rotor power supply frequency $\mathrm{f} 2=15 \mathrm{~Hz}$, In this case the generation frequency:

$$
f_{1}=p_{n} f_{r}+f_{2}=p_{n} \frac{\omega_{f_{2}}}{2 \pi}+f_{2}=2 \frac{109.9557}{2 \pi}+15 \approx 50 H z
$$

Type (8) and (12) are used to calculate the amplitude spectrum, amplitude envelope and instantaneous frequency spectrum demodulation spectrum shown in Figure 3 and 4. In addition to the visible stator current signal of $50 \mathrm{~Hz}$ frequency component, there is no other significant frequency components.

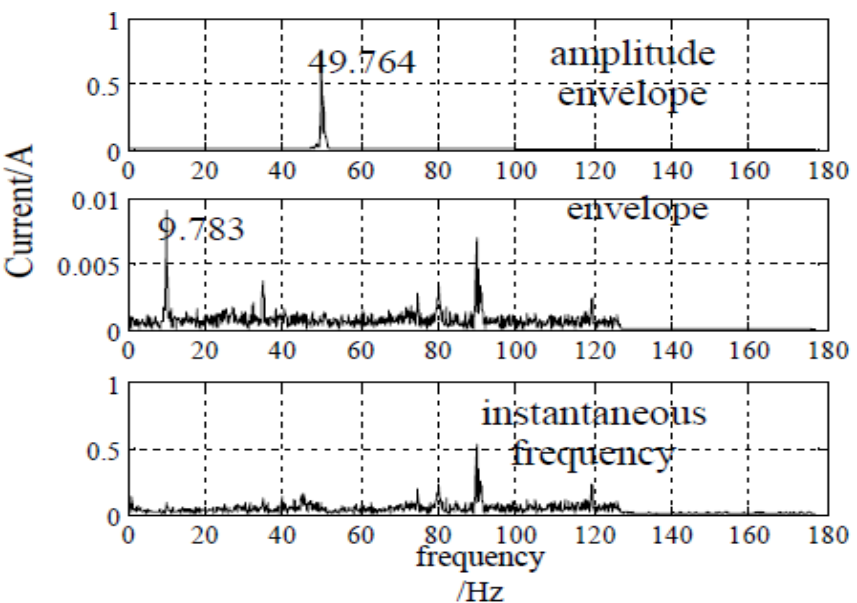

FIGURE III. THE SPECTRUM OF GENERATOR STATOR CURRENT IN NORMAL TIMES (f2=10Hz, $\omega r 2=109.9557 \mathrm{rad} / \mathrm{s}$ )

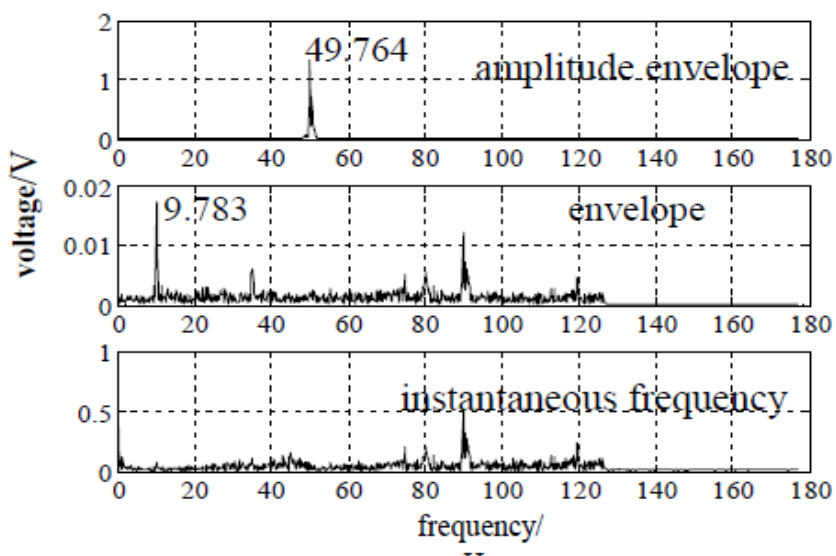

$\mathrm{Hz}$

FIGURE IV. SPECTRUM OF GENERATOR STATOR VOLTAGE IN NORMAL TIMES(f2 $=15 \mathrm{~Hz}, \omega \mathrm{r} 2=109.9557 \mathrm{rad} / \mathrm{s})$ 
B. The Simulation Results Run under Fault Conditions

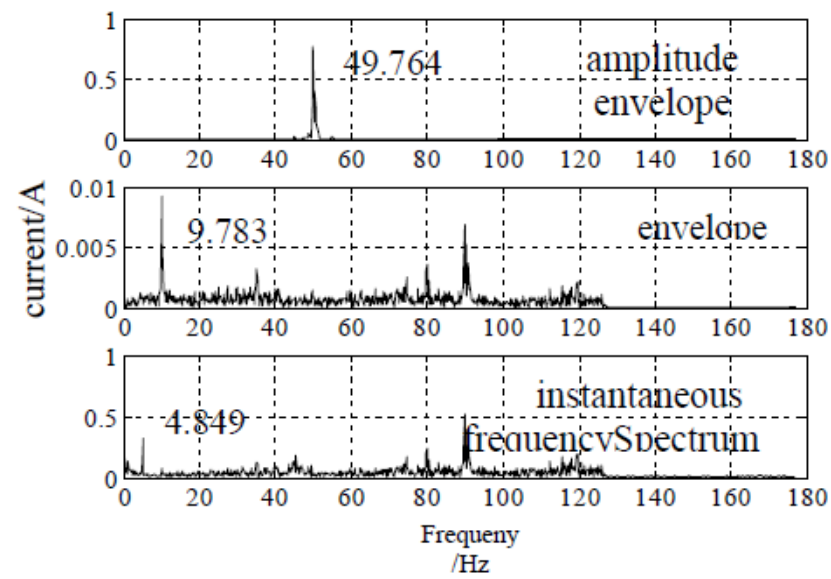

FIGURE V. SPECTRUM OF GENERATOR STATOR CURRENT WHEN SIMULATE FAULT(f2=15 Hz, $\omega \mathrm{r} 2=109.9557 \mathrm{rad} / \mathrm{s})$

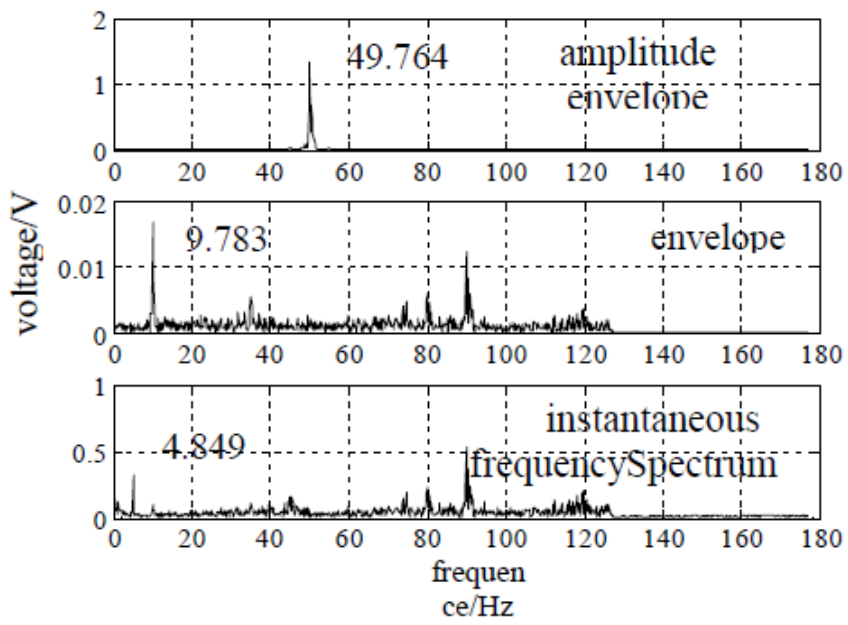

FIGURE VI. SPECTRUM OF GENERATOR STATOR VOLTAGE WHEN SIMULATE FAULT (f2=15 Hz, $\omega \mathrm{r} 2=109.9557 \mathrm{rad} / \mathrm{s}$ )

If the large gear fault is simulated, it only needs to set the failure frequency as the shaft frequency, the stator current and voltage spectrum are shown in Figure 10 and Figure 11 at the moment. Compared with the Figure 3, we can clearly distinguish that the modulation has sideband components at power frequency $(50 \mathrm{~Hz})$ caused by the torque and speed fluctuation in amplitude spectrum. Although modulation components are not found on the envelope spectrum of amplitude, $4.849 \mathrm{~Hz}$ ingredients of speed fluctuation can be clearly obtained in the instantaneous frequency spectrum, which means power frequency fluctuation of generator is mainly caused by speed fluctuation of the broken teeth failure at off-grid state, the fluctuation frequency is consistent with the simulated failure frequency.

\section{Test BENCH Verification OF GeAR SimUlation FAULT}

When the test bench is at the state of failure, current signal of generator stator is collected for signal analysis and processing, which is compared with the processing results of rotational speed signal. Simulated experiment is taken on the test bench. When the rotor frequency of the generator $\mathrm{f} 2$ is 2.5 $\mathrm{Hz}$ and stator frequency of the motor $\mathrm{fl}$ is $10 \mathrm{~Hz}$, the measured frequency spectrum of the phase current signal at the generator stator side is shown in Figure 7. Figure 8 is the spectrum analysis diagram of motor speed signal at the current conditions.
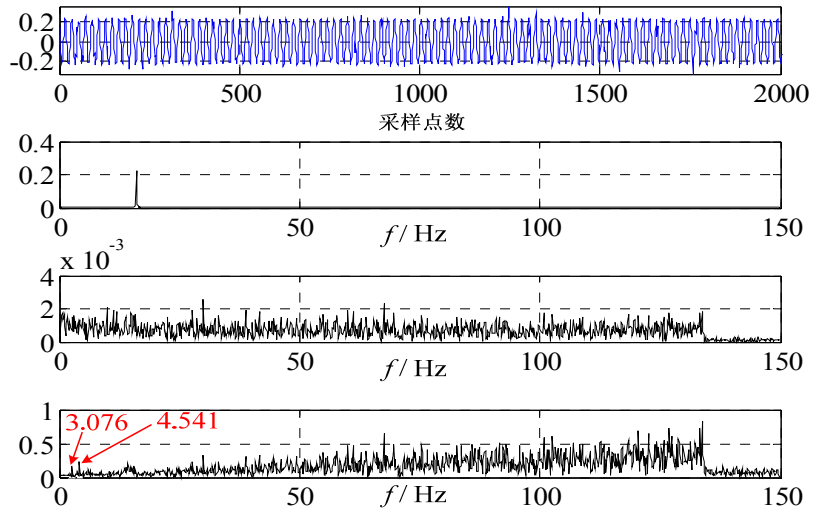

FIGURE VII. SPECTRUM OF GENERATOR STATOR CURRENT IN FAULT TIME(f2 $=2.5 \mathrm{~Hz}, \mathrm{fl}=10 \mathrm{~Hz})$

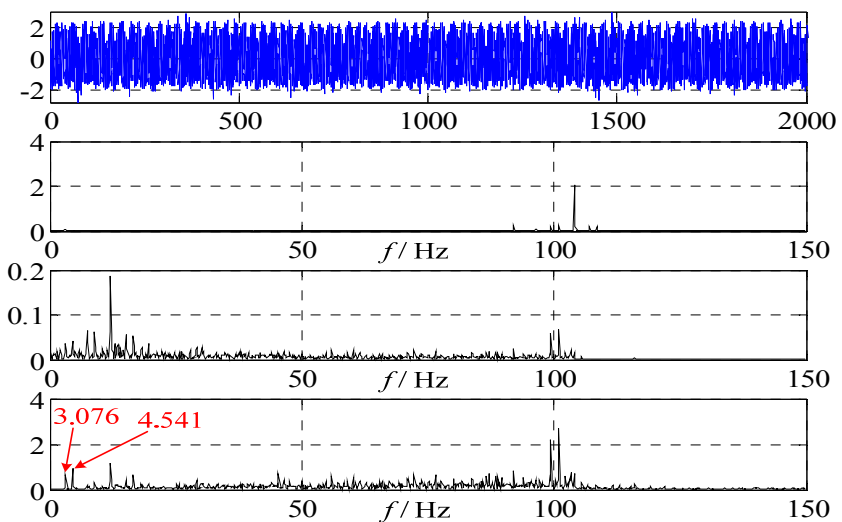

FIGURE VIII. SPECTRUM OF GENERATOR STATOR SPEED IN FAULT TIME(f2 $=2.5 \mathrm{~Hz}, \mathrm{fl}=10 \mathrm{~Hz})$

It can be seen from the Figure 12 that rotating frequency of two gear shafts are $3.076 \mathrm{~Hz}$ and $4.541 \mathrm{~Hz}$, in which $4.541 \mathrm{~Hz}$ is rotating frequency of generator axis. Due to the installation problems of the generator, there is a more or less unbalanced or incorrect phenomenon, this frequency component occurs. Rotating frequency of simulated rotor shaft is $3.076 \mathrm{~Hz}$, which should not appear in generator stator current of normal gear. Actually there is a simulated broken tooth of the large gear on this shaft, which leads to an impact per turn, so the rotation frequency $(3.076 \mathrm{~Hz})$ of the axis is reflected in the generator stator current signal. It also be seen from the Figure 14 the similar situation, so under the contrast of the rotational speed signal, the reflected fault states from current signal is correct.

\section{CONCLUSION}

Through the fault simulation analysis of a double-fed wind generator, we can conclude that the electrical generator stator can reflect mechanical fault information of transmission 
equipment accurately. There are following rules: (1) in the grid environment, the fault information is mainly reflected in the stator current signal, the voltage signal is not sensitive; in the off-grid environment, the fault information of the generator stator current and voltage are more sensitive. The above phenomenon indicates that the off-grid environment is more conducive to fault signal extraction and analysis. (2) in the grid environment, the fault information is mainly reflected in amplitude envelope spectrum, which indicates that the fault information and the main power supply are mainly amplitude modulation relationship; In the off-grid environment, the fault information is mainly reflected in frequency demodulation signal, which indicates that the fault information mainly occurs in the form of frequency modulation, the fluctuation phenomenon of generators power frequency occurs at the same time. Therefore, diagnostic method without sensor can be applied to both the grid and off-grid environment, it can be effective only by choosing suitable demodulation methods according to the circumstance.

\section{ACKNOWLEDGMENT}

This article is funded by the national natural science foundation of China (51275136).

\section{REFERENCES}

[1] Shen Yanxia, Li Fa: Control Engineering of China, Vol.20, No. 3(2013), pp.789.(in Chinese)

[2] Chen Xuefeng, Li Jimeng, Cheng Hang, et al. : Journal of Mechanical Engineering, Vol.47, No. 9(2011), pp.45.(in Chinese)

[3] Yang Wenxian, Tavner P. J. and Crabtree C.J., et al. :IEEE Transaction on Industrial Electronics, Vol. 57, No. 1(2010), pp. 2631

[4] Gong Xiang, Qiao Wei, Zhou Wei. in: Proceedings -IECON 2010, 36th Annual Conference of the IEEE Industrial Electronics Society, (2010), pp. 2615.

[5] Amirat Y., Choqueuse V. and Benbouzid M.E.H., et al. in: 19th International Conference on Electrical Machines-ICEM 2010,(2010),pp.1.

[6] WANG Xingwu, ZHANG Zhaoya,WU Yongli. Computer Simulation, Vol. 26, No. 10(2009), pp. 294. (in Chinese)

[7] Wang Ruilin, Xie Da,Wang Xitian, et. al. Electrical Automation, Vol.33, No. 1(2011),pp. 51. (in Chinese)

[8] Shi Xianjiang, Guo Hua, Shao Junpeng. Journal of Vibration, Measurement \& Diagnosis, Vol.29, No. 3(2009), pp. 352. (in Chinese). 